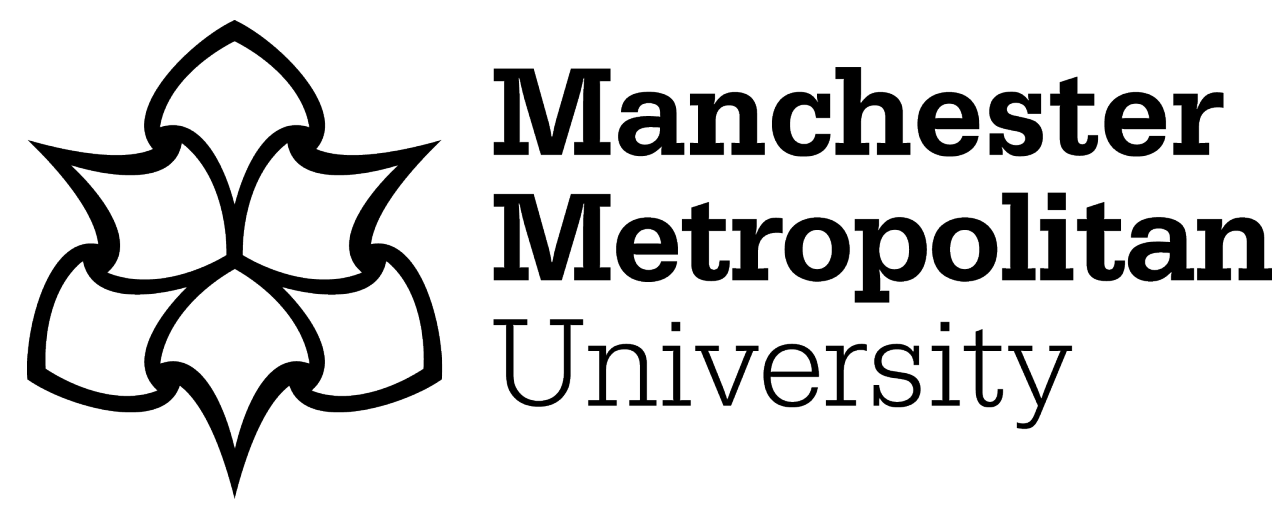

Goulding, JS and Lou, ECW (2013) E-readiness in construction: An incongruous paradigm of variables. Architectural Engineering and Design Management, 9 (4). pp. 265-280. ISSN 1745-2007

Downloaded from: https://e-space.mmu.ac.uk/620524/

Publisher: Taylor \& Francis

DOI: https://doi.org/10.1080/17452007.2013.775099

Please cite the published version 


\section{E-Readiness in Construction: An Incongruous Paradigm of Variables}

\section{INTRODUCTION}

Knowledge is an essential and critical function needed in order to obtain and facilitate competitive advantage in organisations. It is also becoming increasingly more important for organisations to manage, as it is now recognised as being a valuable resource that can help an organisation's ability to innovate and compete (Carneiro, 2000). Knowledge therefore, exists both within individual employees, and within organisations (Bollinger and Smith, 2001). In this respect, today's organisations are increasingly paying more attention to the initiation and leverage of knowledge management (KM) activities for building their assets (intellectual capital) and knowledge-based systems (processes) in order to maximise results (Chauvel and Despres, 2002). Given this inertia, it is advocated that KM strategies must do more than just achieve outline high-level goals such as "becoming a knowledge-enabled organisation". The strategy must identify the key needs and issues within the organisation, using frameworks that specifically address core business issues, supported by assessment techniques that are able to evaluate the effectiveness and efficacy of the strategy in question. More specifically, they should be able to successfully measure the impact of KM initiatives on an organisation's capability. This alignment to organisational strategic goals and objectives is important (Carrillo et al, 2003; Robertson, 2004), as if structured and aligned appropriately, it can be used to create revolutionary change through formal KM frameworks (Liebowitz, and Megbolugbe, 2003; Kridan and Goulding, 2006). Organisations therefore need to capitalise on the potential value of knowledge (Kim, 1999, Nonaka, 1991), and this is often where the greatest KM challenges lie (Cong and Pandya, 2003). It should therefore be incorporated within an organisation's strategic goals and objectives (Carrillo et al, 2003; Anumba et al, 2005; Easterby-Smith, and Lyles, 2003). These issues naturally impinge upon the concepts and development of Organisational Learning (Argyris and Schon, 1978; Senge, 1990; Huber, 1991), the principal tenet of which is to structure the collective actions of individuals to improve organisational knowledge. There are numerous issues concerning the optimisation of KM in organisations, the main issues of which relate to: information and communication technology (ICT) focus, organisation commitment, change management procedures, and process management.

Against the backdrop and importance of KM rests the need for construction organisations to be "fit-for-purpose" in order to remain competitive. Advocates have long acknowledged the importance of ICT for creating strategic advantage (Betts et al, 1991; Hua, 2007), but evidence in extant literature has yet to identify the precise levers and drivers of success, nor have provided organisations with formal blueprints to adopt for being e-ready (to absorb technology within their organisational setting). Whilst KM can be seen to help organisational success (Offsey, 1997; Bhatt, 2001), it also has to be acknowledged from a construction perspective that this will require organisations to change (Cox, 1996; Barlow and Jashapara, 1998; Kululanga et al., 1999; Love et al., 2000). Moreover, as ICT is continually evolving, competitive advantage is high on the agenda (European Commission, 2006). However, investment in ICT often fails to bring about competitive advantage or meet the expected business objectives due to several multi-layered reasons (Alshawi, 2007). One of the main inhibitors to ICT investment seems to be the lack of 'know-how' or availability of structured mechanisms which can guide managers and key decision makers to successfully absorb new technologies into their work practices (Construct IT, 2008). In addition, similar tangential studies have identified that in some cases $75 \%$ of ICT investments within the construction domain failed to meet their anticipated business objectives (Salah, 2003). This acknowledgement evidenced that projects were either abandoned, significantly redirected, or even worse, "kept alive" in spite of these failures. In this respect, 'missed opportunities' and 'wasted resources' has engendered a somewhat cautious risk-averse approach to ICT investment decision-making. It is therefore important that construction organisations are in a state of 'readiness' in order to fully and effectively absorb IT enabled innovation into their work practices prior to any investment.

Exemplars of ICT innovation cover a wide range of remits, from project management, through to electronic data management (Nitithamyong and Skibniewski, 2004; Hjelt and Björk, 2006). However, whilst it is continually acknowledged that the construction industry has great potential for the uptake of ICT and e-business (Anumba and Ruikar, 2002), it also appears that some fundamental problems still exist. Some of these issues include: organisational factors (people and process); the enabling environment and supportive infrastructure, and the actual technology itself. For example, Basu and Jarnagin (2008) noted that a "metaphorical glass wall" exists where business executives are not fully able to recognise the full functionality and value of technology to their business vis-à-vis process and markets, nor did IT personnel possess an understanding of the strategic objectives of the business. Moreover, failures such as these could also be associated with a misalignment of fit between the social actions and the technical systems (Ngwenyama and Lyytinen, 1997). This resonates with the findings by Goulding et al. (2007) regarding the importance of understanding technology adoption and diffusion issues, and with findings by Mata et al. (1995) concerning investment decision-making. Notwithstanding these factors, it is therefore important to acknowledge that implementing advanced ICT applications within a construction environment in order to create opportunities and develop sustainable competitive advantage can only be leveraged by improving processes in line with management objectives; along with a deep and rich understanding 
of the actual technology itself, and the impact this can have on the people using it (Alshawi, 2007). E-business in construction now plays an important part of organisational success, from KM through to procurement, trust, and governance (Anumba and Ruikar, 2009). Moreover, as Building Information Modelling is continuing to gain momentum, new indictors and drivers are emerging (Suermann and Issa, 2009), along with new architectures for exploitation (Isikdag, 2012).

This paper focuses on the dominant factors that can often facilitate successful implementation of ICT within the construction industry in terms of achieving its primary business objectives in order to be 'e-ready'. This paper introduces the causal relationships and drivers of ICT, and examines the dynamic environment within which construction businesses operate in order to highlight the seminal relationship between business process, people and technology. This is followed by a detailed discussion of two scoping studies that examined the importance of core drivers and levers of change; and the ways in which these could be proactively harnessed through the development an e-readiness framework in order to help organisations better align and augment their resources to maximise success.

\section{THE CONSTRUCTION INDUSTRY AND ICT}

The fragmented nature of the construction industry (CI) (Emmerson, 1962; Banwell 1964; Latham, 1994; Egan, 1998) has often been cited as a primary factor that has adversely affected performance and productivity. In this respect, whilst contemporary 'change' initiatives have tried to improve performance by focussing on time, quality or cost elements, other strands of research have attempted to investigate the importance of core strategic and operational needs (Betts et al., 1991; Betts, 1992; Ahmad et al., 1995; Venegas and Alarcón, 1997; Kumaraswamy, 1997). For example, several studies have evaluated the role of ICT within the construction sector, the work of which has included investment (Love et al., 2005; Tse and Choy, 2005; Dehlin and Olofsson, 2008), through to training (Goulding and Alshawi, 2002; Zou and Seo, 2006), adoption and user resistance (Hartmann and Fischer, 2009; Ahuja et al., 2009), and ICT diffusion (Peansupap and Walker, 2004). Notwithstanding these studies, it is important to understand ICT in order to disentangle tangible benefits from intangible benefits (Ward and Daniel, 2005), along with "technology push" and "market pull" factors (Reddy, 1996) in order to fully appreciate these interdependencies.

Data, information, knowledge and intelligence, in any terms, drive the CI (Robinson et al., 2006; Senaratne and Sexton, 2008), and this is now recognised as an essential organisational resource to achieve sustainable competitive advantage (Egbu, 2004). The ability of organisations to capture, store and reuse information, both tacit and explicit, can bring unprecedented wealth of knowledge to the employees within the organisation and also the wider supply chain (Nanoka and Takeuchi, 1995). In this respect, ICT can fast-track this process. For example, explicit knowledge can be captured and stored in databases and indexed for intelligent searching; whereas, tacit knowledge can be captured through electronic communication (e.g. e-mails, blogs, podcast, etc.) for storage, indexing and retrieval (Bigliardi, 2010; Egbu and Botterill, 2002). This raises the question again, "are we ready to use ICT to accelerate organisational processes?". Ostensibly, in most industries it is essential to deploy the right ICT solutions to the right processes, at the right level and at the right time. However, within the construction industry, more often than not, these "rights" are often misunderstood and therefore compromised at the early stages of inception (Alshawi, 2007).

The "acceptable" level of ICT that can be successfully utilised in an organisation, (e.g. ensuring its business benefits are realised), depends on assessing a range of critical issues needed to ensure a balance between the organisation's readiness (mainly factors required to adapt to the proposed change) against the level and complexity of the proposed IT (which can often hinder/limit success) (Alshawi, 2007; Tran et al., 2011). This balance often includes many issues such as: capital expenditure, resource availability, organisation's maturity and readiness, culture and vision, and available IS/IT skills. Following these issues, readiness can be defined as the ability of an organisation or economy to deploy Internet-based computers and information technologies to transform traditional businesses into a new economy - an economy that is characterised by the ability to perform business transactions in real-time - in any form, anywhere, anytime, and at any price (Bui et al., 2002; Kaplan and Norton, 2004; Lou and Goulding, 2010). In this context, the term "e-readiness" is coined to measure the degree to which an organisation may be ready, prepared, or willing to obtain benefits, which arises from the digital economy. It is concerned with the organisational soft issues such as business processes, management structure, change management, people and culture. The importance of organisational e-readiness to successfully embrace IT into work practices is gathering pace both in academia and industry due to the large investments in IT over the past decade of which a large percentage have failed to meet their intended business objectives (Krigsman, M. 2010; Lientz and Larssen, 2006; Michaelson 2006; Soroor et al., 2009).

\section{E-Readiness: People, Process, Technology}

The CI is predominantly project-oriented, where teams of companies get together to design, construct and maintain a construction project, and the team is then disbanded after the project has been completed. Whilst it can be argued that the industry's main functions and processes are still relatively unchanged, there has been a 
challenge to improve performance and reduce costs using ICT as a lever of change (Marsh and Flanagan, 2000). However, although the potential to improve performance still exists, efforts have been hampered by 1) the industry's structure; 2) the fragmented supply chain; 3) lack of investment in ICT; 4) limited ICT 'champions' who are able to understand innovation opportunities; and 5) limited support and empowerment of senior decision makers (Lou and Alshawi, 2009). In this respect, there are three critical elements that can significantly influence the level of ICT project integration, specifically: 1) process alignment (the ability to align organisational processes with the proposed system's functionalities); and 2) people (the ability of employees to accept and adapt to the system); 3) technology (the ability of the ICT to simplify processes with minimal people involvement). Thus, the relationship between people, process and technology are common themes and enablers of e-readiness. These elements are highly interrelated, as developing competence in one element must be accompanied by improvement in the others.

\section{Process}

Businesses tend to operate in complex contexts of regulatory policies and institutional arrangements that set and govern the rules of action in a competitive market place (Brady et al., 2008). Therefore, the existence of an effective communication and information process reflects transparency and predictability of regulatory implementation, openness of organisational policies and (political and business) stability of the organisation (Loukis et al., 2008; Peansupap and Walker, 2005). Fundamental elements in creating and managing change for organisation readiness includes a deep understanding of the need for change (Sarabia, 2007; Craig and Sommerville, 2006), along with the knowledge, skills and abilities of the workforce needed (Noe, 2005), as the retention of intellectual capital and knowledge are vital for supporting the organisation's mission, vision and strategic goals (Ulrich and Brockbonk, 2005), and can be seen as core drivers of success (Cappelli, 2008; de Jong and Den Hartog, 2007; Grote, 2005; Applegate, 2008). From literature reviews and references above, Process readiness enablers include business and information processes; information access and connectivity; security and integrity; policy and vision; knowledge sharing and capture; services and support; networked economy; and web measures and services, as shown in Table 1.

\section{People}

People are core drivers of a business. As a collective force, they can add true value to organisational e-readiness. Mulcahy (1990) observes that for construction organisations to be successful, they must have clear objectives recognising the markets it wishes to address, services it wishes to provide, risk it may carry, structure it will use, the environment it will operate within, controls it will put in place, and the returns it wishes to achieve. Therefore, the ability to work collaboratively, specifically, the provision to obtain the right information, by the right people, at the right time is paramount (Lou and Alshawi, 2009). This mandate requires the capture and dissemination of knowledge as a central organising theme for business change, seen as continuous adaptation and innovation - concurrently tracking the outside world and internal capabilities, and linking the two together (Chan and Chao, 2008). Leadership also plays a vital role for communicating and driving forward a clear vision and strategy (Hammer and Stanton, 1995). The complete list of People readiness enablers is shown in Table 1.

\section{Technology}

Historically, technology was often used as an indicator of advancement in organisations - the more "hi-tech" technology was used, the more advanced the organisation was perceived to be. This is not the case anymore, as organisations are increasingly measured by the benefits and optimal use of their technology (Basu and Jarnagin, 2008; Marsh and Flanagan, 2000). Whilst it is acknowledged that new technologies can be seen as being 'attractive' from a business perspective, especially when they can offer quantifiable benefits to one or more stakeholder groups, it is always wise to analyse these perceived benefits beforehand. For example, benefits might be tangible, such as reduced cost or reduced risk, or they may be intangible (but still quantifiable), such as enhanced corporate or community image (Keillor, 2007; Lin et al., 2007). Whilst constant development of new technologies is now seen as technology "levellers" (Zsidisin et al., 2004), it is much more important to consider the integration of this technology into organisational process (Aranda-Mena, 2009; Anumba et al., 2008; Lee and Sexton, 2007; Cheng et al., 2001). Therefore, if companies wish to strategically leverage the full potential of ICT, then they must also evaluate its direct and indirect benefits prior to implementation, as any investment often forms considerable part of a company's capital expenditure (Alshawi et al., 2003; Gyampoh-Vidogah et al., 1999; Peansupap and Walker, 2006;). Table 1 list the Technology readiness enablers.

In summary, seminal literature reports on three main recurring themes, specifically: people, process and technology. These themes are considered important drivers for further investigation in order to determine organisational e-readiness priorities. In particular, it is important to understand organisational thinking, especially where organisations are aspiring to achieve innovation or niche area competitive advantage.

\section{RESEARCH AIM AND METHODOLOGICAL APPROACH}

Epistemology reflects on the methods and standards through which reliable and verifiable knowledge can be produced (Partington, 2002). Given this, and accepting the links between epistemology and research methods 
often entails a characterisation from the Natural Sciences, a cross-sectional approach was adopted in order to focus on specific cases and their unique context (Bryman and Bell, 2007). The aim of this research was to develop an e-readiness 'conceptual' framework that enables construction organisations to quantify and measure organisational e-readiness through the enablers from the people, process and technology perspective. This approach was used to develop a foundation of 'building blocks' to help large multinational construction organisations understand the importance of aligning variables into a coherent strategic roadmap. The research methodological approach adopted for this study used two interrelated scoping studies to help identify current thinking in order to determine priorities, governing parameters, and a shared congruent vision of the way forward. Synthesis of extant literature helped to identify the core readiness enablers, which were categorised into three main themes: people, process, and technology (Table 1). These themes were used to develop the questionnaire constructs for data capture purposes. These questionnaires were pre-piloted with four domain experts prior to the survey being undertaken in order to validate content and address issues concerning semantics (as some of the terminology used encompassed both the business sector and the IT sector). The research lens adopted aimed to gauge perception of opinions and aspirations based on experience within the industry. As ranking is particularly useful for determining social values (Alwin and Krosnick, 1985), this approach was adopted for eliciting the relative importance of respondents through prioritisation. This approach is in line with similar discovery-oriented inquiries (Gubrium and Holstein, 2001; Denzin and Lincoln, 2005).

\section{Scoping Study One}

Scoping study one was used to identify the top three people, process and technology theme enablers and current thinking regarding e-readiness within the construction domain. In particular, it was undertaken in order to investigate, understand and explore the state of the UK Construction Industry (CI) with specific interest in the organisational e-readiness and performance measurement. The rationale of this was to:

1. Understand the nature, culture and history of the $\mathrm{CI}$ in terms of:

- existing problems, progress made

- standardisation, national development issues

- future thinking

2. Understand the underlying concepts, progress and uptake of e-readiness in the $\mathrm{CI}$ in terms of:

- evolution, progress and acceptance of e-readiness

- acceptance of e-readiness

- impact and stimulus of e-readiness

3. Understand the underlying concepts, dynamics and practice of organisational performance measurement in the $\mathrm{CI}$ in terms of:

- evolution, progress and acceptance of organisational performance measurements

- acceptance of organisational performance measurements

- impact and stimulus of organisational performance measurement

In this respect, it was deemed important to understand the thinking, maturity and uptake of ICT investment among industry leaders and innovators (e.g. Chief Executives, ICT Directors, Innovation Directors) of leading construction contracting and consulting multinational organisations based in the UK. This was needed in order to help establish the evolving use and uptake of ICT in relation to the industry's past and current understanding of the value of ICT to innovation and continuous improvement (with a view of relating this to the e-readiness of organisations). Tangential to this, was the need to understand the current developments, uptake and breakthrough initiatives in the construction industry, particularly regarding unravelling ICT evaluation and organisational readiness. This therefore needed to embed current thinking on people, process, and technology. The final part of this investigation needed to understand current thinking on e-readiness and performance measurement within the construction industry in order to relate theory with grounded practice. In order to tease out these important issues, scoping study one used 20 respondents deemed domain experts in their respective field to identify the causal drivers needed to improve industry performance through the innovative application of ICT As a catalyst for exploitation. All respondents held senior positions within the industry, and included such roles as company directors, chief finance officers, senior project managers etc. The domain experts were asked to rank the importance of eight criteria across the three themes of People [Leadership and Empowerment; Culture and Society; Human Capital and Skills; Learning/Higher Education/Training; Promotion and Facilitation / Support; Change Management; Communication; Capacity Building]; Process [Business and Information Process; Information Access and Connectivity; Security and Integrity; Policy/Strategy/Vision; Knowledge Sharing and Capture; Services and Support; e-Processes (efficiency / maturity); Web Connectivity and externalisation] and Technology [Connectivity and Security; ICT Infrastructure (hardware); ICT Reliability and Support; Use/Trial of New Technologies; Technology Investments; Management of Information; ICT Sharability / Interoperability; Technology Transfer and Diffusion]. A short semi-structured interview was then undertaken with each respondent in order to confirm findings and the opportunity for the domain experts to voice out any additional 
themes or enablers. Each enabler was derived from literature review and form potential key recommendations for the CI to be electronically ready (Lou and Goulding, 2010). The top three enablers from each theme (people, process, technology) are then brought to Scoping Study 2 to be ranked again. Interview sessions with the 20 domain experts did not raise any additional themes or enablers.

\section{Scoping Study Two}

Scoping study two used the findings from scoping study one as a basis for determining a deeper and richer understanding of the results obtained. In this respect, a different sample set of 20 respondents was chosen, albeit with the caveat of being considered domain experts in their respective field (and having similar role identifiers as described in scoping study one). This study was carried out to reinforce the results conducted in the first study, as well as to highlight the importance of e-readiness to the wider CI in the UK. In particular, this study aimed to tease out specific understanding regarding senior executives' thinking on the adoption and future use of ereadiness in the CI. The study was performed during the Construction Industry Research and Information Association's (CIRIA) Annual Lecture entitled 'Sustainable Competitive Organisations' in London (CIRIA, 2009). These 20 domain experts were asked to determine the importance of criteria across three themes of $e$ readiness [Leadership and Empowerment; Change Management; ICT Sharability/ Interoperability; Technology Investments; Business and Information Process; e-Processes (efficiency/maturity); Policy/Strategy/Vision], help needed [Awareness/Education Programmes; Executive Briefings; Facilitating Networking; e-Readiness Assessment Tools; Securing Government Funding], and collaboration [Establishing Network/Community of Practice; Focus Groups; Developing Case Studies; Workshops/Seminars; Research]. To further qualify these results, short interview sessions were conducted after the survey in order to reaffirm respondents' perceptions and to confirm findings.

\section{RESEARCH FINDINGS AND DISCUSSION}

Scoping Study One presented a questionnaire to 20 domain experts covering three core areas (people, process, technology), over 24 enablers. The domain experts, consisting of industry practitioners (18) from and academics (2); where 4 are Senior Executives (Directors), 14 Managers and 2 Senior Academics. Participants were given a questionnaire and asked to rate the importance of the themes in percentage terms, and rank the enablers within each theme. Short interview sessions were conducted to reinforce the results of the study, as well as to fill in the gaps of any unidentified themes or enablers. Research findings identified that respondents' favoured the "Process" theme as being dominant, having the highest potential impact for achieving e-readiness in an organisation (39.4\%), followed closely by the "People" theme (37.9\%), then the "Technology" theme (22.7\%). These results can be seen in Figure 1.

From Figure 1, it can be seen that respondents' had difficulty determining the dominant theme between the "Process", and "People" themes [1.5\% differential]. It was therefore postulated at this juncture that respondents' did not perceive technology to be the issue (as it was more important to focus on the people and processes within the organisation first. This assumption was therefore carried over to Scoping Study Two for further investigation. Furthermore, within the "People" theme, 'leadership and empowerment' was selected to be the top enabler, followed by 'change management' and 'human capital and skills', the results of which can be seen in Figure 2. Interview respondents also highlighted the importance of the cohesion of the elements - people, process and technology. The interviewees also express that if a single element does not function well, the entire concept of e-readiness will fail. In interesting comment from an IT Director of a multinational construction organisation states that 'an organisation cannot be ready when their technology adaption is low or non-existent (not willing to try or invest in new technologies) while their staff have high technical capability and robust work process'.

Results obtained for the "Process" enabler category identified the main important drivers as being 'e-processes' (maturity and efficiency of e-processes in the business) followed by 'business and information process' and 'policy/strategy/vision', the results of which can be seen in Figure 3. These results indicate that there is a strong correlation between these three areas [2.24, 2.35, and 3.00 respectively], demonstrating the importance of linking e-processes to the core business drivers and strategic vision of the company. Conversely however, respondents did not seem too concerned over the technological process themes relating to 'security and integrity', or 'web connectivity and externalisation'. This may be because respondents lacked domain specific competence in process technology (as respondents were all strategic decision makers), or because their tacit knowledge from previous projects negated these themes in deference to their preferred choice.

Results obtained for the "Technology" theme category identified the main important drivers for construction organisations as being 'ICT sharability/interoperability' and the 'management of information', the results of which can be seen in Figure 4. This resonates strongly with the need to align information to core business processes, which as a precursor, requires 'change management' and 'leadership/empowerment' in place in order to make this happen. Furthermore, these findings demonstrate the perception that e-readiness within construction 
is not purely driven by technology per se, but more by its people and processes, and the importance of understanding the 'soft issues' needed in order to achieve organisational e-readiness.

Scoping Study Two used a different set of domain experts, consisting of 9 Senior Executives (Chairmen and Directors), 10 Managers, 1 Senior Academic and 1 postgraduate student - all from the construction industry; where 18 are industry practitioners and 2 from academia. Research findings noted that the top two themes deemed most important for leveraging e-readiness within construction organisations were 'Leadership and Empowerment', followed by 'Business and Information process', the results of which can be seen in Figure 5. These top two themes resonate with findings derived from Scoping Studies One. However, an important issue to note at this juncture is the apparent perception that investment in technology did not seem to be a major concern to respondents $(2.7 \%)$, nor was the need for e-process maturity (5.4\%).

The final part of Scoping Study Two was used to determine the level of support needed by key decision makers to ensure the industry fully engaged with the concept of e-readiness. In this respect, questions were asked regarding the need for various support mechanisms. Research findings identified that the main support mechanism needed from a priority perspective was the need for e-readiness assessment tools (36\%) in order for them to gauge their e-readiness maturity. Follow up interview sessions on this matter indicated that no formal product or framework seemed to exist to help them with this. The next most important priority area identified was the need for education awareness support (20\%). The preferred mechanism for achieving this was identified as being through e-readiness case studies and research programmes. Interviewees also brought forward another potential collaborative exercise - partnerships, as these were seen as a way of refining the framework and updating any themes or enablers.

In summary, similar studies of this nature have attempted to provide insight into e-readiness, from governmental support (Jutla et al, 2002), through to governance (Potnis, 2010), and e-market innovation adoption (Johnson, 2010). The scoping studies presented in this paper demonstrated a lack of understanding of the core e-readiness issues currently facing the Construction Industry. From the 40 key decision makers polled in this research, only through follow-up face-to-face interviews was it apparent that e-readiness with the construction sector was still in its infancy. However, it was also clear that respondents were starting to move these issues forward through individual in-house company initiatives, as it was apparent that no formal Communities of Practice/Steering Committees or framework tools currently existed to help organisations with the e-readiness transition processes needed. Using the finding from Scoping Study One and Scoping Study Two, the top five e-readiness core enablers were identified as being: Leadership \& Empowerment (\#1); Change Management (\#2); Business \& Information Process (\#3); Policy/Strategy/Vision (\#4); and ICT Sharability/Interoperability (\#5), the results of which can be seen in Table 2 .

\section{CONCLUSION}

The Construction Industry is continuing to operate in a fragmented but dynamic and highly competitive environment. In this respect, key decision makers are continually trying to find new ways of driving forward their businesses. With unprecedented levels of technological change now increasingly being used as a means through which competitive advantage can be leveraged, this research aimed to determine the UK Construction Industry's perception on how businesses will have to change, from the way they are currently doing business to a more direct, structured and proactive approach (if they are going to be in a strong position to leverage ereadiness opportunities in the future). Research findings from two scoping studies covering 40 domain experts identified the notion that a trichotomy of primary causal themes existed, specifically: People (39\%), Process (38\%) and Technology (23\%). Whilst these were recognised as the main underpinning themes, with leadership and empowerment, managing business and information processes, and change management seen as the main enablers; it is also important to note that of the five main enablers identified in Table 2, the top issues focussed on the 'People', 'Process' and 'Technology' themes. These findings suggest that the industry does not perceive the solution to becoming e-ready as being predominantly technology-driven, but more through the engagement of leadership (which aligns change management issues to business processes and strategic vision). However, whilst this aspiration is reported and acknowledged, it is also important to note that the industry now recognises the importance of using e-readiness assessment tools to help them shape this transition. In this respect, similar assessment tools in other industry sectors tools have highlighted several benefits and opportunities (Mutula and Van Brakel, 2006; Hanafizadeh et al., 2009; Rodríguez, and Meseguer, 2010).

This research used a mixed method approach for its research methodology, the augmentation of which used two interrelated scoping studies for the collection and analysis of data. These scoping studies used 40 domain experts from the UK's construction sector, the granularity of which represented a diverse cross section of expertise that embraced SME's through to large construction conglomerates. Whilst the data veracity, validity and sample set coherence can be considered robust and defendable from a generalisability and repeatability perspective, it is important to acknowledge the importance of context. 


\section{REFERENCES}

Ahmad, I., Russell, J. and Abou-Zeid, A. (1995), "Information Technology (IT) and Integration in the Construction Industry", Construction Management and Economics Journal, 13(2), 163-171.

Ahuja, V., Yang, J. and Shankar, R. (2009), "Study of ICT adoption for building project management in the Indian construction industry", Automation in Construction, 18(4), 415-423.

Alshawi, M. (2007), Rethinking IT in Construction and Engineering: Organisational Readiness, Taylor and Francis, UK.

Alshawi, S., Irani, Z. and Baldwin, L. (2003), "Benchmarking information technology investment and benefits extraction", Benchmarking: An International Journal, 10(4), 414-423.

Alwin, D.F., and Krosnick, J.A., (1985), "The Measurement of Values in Surveys: A Comparison of Ratings and Rankings", Public Opinion Quarterly, 49(4), 535-552

Anumba, C. and Ruikar, K. (2002), "Electronic Commerce in Construction - trends and prospects", Automation in Construction, 11, 265-275.

Anumba, C, Egbu, C. and Carrillo, P. (2005), Knowledge Management in Construction, Blackwell Publishing, UK.

Anumba, C.J., Pan, J., Issa, R.R.A. and Mutis, I. (2008), "Collaborative project information management in a semantic web environment", Engineering, Construction and Architectural Management, 15(1), 78-94.

Anumba, C. J. and Ruikar, K. (eds) (2009), "Front Matter", in e-Business in Construction, Wiley-Blackwell, Oxford, UK

Applegate, B. (2008), "Challenges and Opportunities in Nonprofit Capacity Building", Nonprofit World, 23.

Aranda-Mena, G., Crawford, J., Chevez, A. and Froese, T. (2009), "Building information modelling demystified: does it make business sense to adopt BIM?", International Journal of Managing Projects in Business, 2(3), $419-433$.

Argyris, C. and Schon, D.A. (1978), Organizational Learning: A Theory of Action Perspective, AddisonWesley, Massachusetts, USA.

Banwell, H. (1964), The Placing and Management of Building Contract, The Banwell Report, HMSO, London, UK.

Barlow, J. and Jashapara, A. (1998), "Organisational Learning and Inter-Firm "Partnering" in the UK Construction Industry", The Learning Organization Journal, 5(2), 86-98.

Basu, A. and Jarnagin, C. (2008), "How to Tap IT's Hidden Potential", Wall Street Journal, http://online.wsj.com/article/SB120467900166211989.html [Date accessed 17 June 2010]

Betts, M. (1992), "How Strategic is Our Use of Information Technology in the Construction Sector", International Journal of Construction Information Technology, 1(1), 79-97.

Betts, M., Cher, L., Mathur, K. and Ofari, G. (1991), "Strategies for the Construction Sector in the Information Technology Era", Journal of Construction Economics and Management, 9(6), 509-528.

Bhatt, G. (2001), "Knowledge Management in Organisations: Examining the Integration between Technologies", Techniques and People, Journal of Knowledge Management, 5, 168-75.

Bigliardi, B., Dormio, A.I. and Galati, F. (2010) "ICTs and knowledge management: an Italian case study of a construction company", Measuring Business Excellence, 14(3), 16-29.

Bollinger, S. and Smith, D. (2001), "Managing organisational knowledge as a strategic asset", Journal of Knowledge Management, 5(1), 8-18.

Brady, M., Fellenz, M.R. and Brookes, R. (2008), "Researching the role of information and communications technology (ICT) in contemporary marketing practices", Journal of Business and Industrial Marketing, 23(2), 108-114.

Bryman, A., and Bell, E., (2007), Business Research Methods, $2^{\text {nd }}$ Ed., Oxford University Press, Oxford, UK

Cappelli, P. (2008), “Talent Management for the Twenty-First Century”, Harvard Business Review, March 2008.

Carneiro, A. (2000), "How does knowledge management influence innovation and competitiveness?", Journal of Knowledge Management, 4, 287-298.

Carrillo, P., Robinson, H., Anumba, C., and Al-Ghassani, A. (2003), "IMPaKT: A Framework for Linking Knowledge Management to Business Performance", Electronic Journal of Knowledge Management, 1(1), 112.

Chan, I. and Chao, C-K. (2008), "Knowledge Management in Small and Medium-Sized Enterprises", Communications of the ACM, 51(4), 83-88.

Chauvel, D. and Despres, C. (2002), “A Review of Survey Research In Knowledge Management: 1997-2001", Journal of Knowledge Management, 6(3), 207-223.

Cheng, E.W.L., Li, H., Love, P.E.D. and Irani, Z. (2001), "An e-business model to support supply chain activities in construction", Logistics Information Management, 14(1/2), 68-77.

CIRIA (2009), CIRIA's Annual Lecture: Sustainable competitive organisations, London, UK. http://www.ciria.org/service/My_Documents/AM/ContentManagerNet/ContentDisplay.aspx?Section=My_D ocuments\&ContentID $=13260$ [Date accessed 15 July 2009]

Cong, X, and Pandya, K.V. (2003), "Issues of Knowledge Management in the Public Sector", UK Electronic Journal of Knowledge Management, 1(2), 25-33. 
Construct IT (2008), Strategic Positioning of IT in Construction. An Industry Leader's Perspective, Construct IT for Business, Salford, Greater Manchester, UK.

Construct IT (2009), Construct IT for Business, Salford, Greater Manchester, UK. http://www.constructit.org.uk/ [Date accessed 11 March 2009]

Cox, R.F. (1996), "Understanding the Linkage Between Individual and Organizational Performance", Proceedings of the CIB W89 Beijing International Conference, Beijing, China.

Craig, N. and Sommerville, J. (2006), "Information management systems on construction projects: case reviews", Records Management Journal, 16(3), 131-148.

de Jong, J.P.J and Den Hartog, D.N. (2007), "How leaders influence employees' innovative behaviour", European Journal of Innovation Management, 10(1), 41-64.

Dehlin, S. and Olofsson, T. (2008) "An evaluation model for ICT investments in construction projects", ITcon, 13, Special Issue Case studies of BIM use, 343-361.

Denzin, N.K, and Lincoln, Y.S (2005), The SAGE Handbook of Qualitative Research, Sage Publications, Third Edition. CA, USA.

Easterby-Smith, M. and Lyles, M.A., (2003), The Blackwell Handbook of Organizational Learning and Knowledge Management, Blackwell Publishing Ltd, Oxford, UK.

Egan, J. (1998) Rethinking Construction: The Report of the Construction Task Force, Blackwell Science, UK.

Egbu, C.O. (2004), "Managing knowledge and intellectual capital for improved organizational innovations in the construction industry: an examination of critical success factors", Engineering Construction and Architectural Management, 11(5), 301-315.

Egbu, C.O. and Botterill, K. (2002), "Information technologies for knowledge management: their usage and effectiveness", ITCon, 7, 125-137.

Emerson H. (1962), Survey of Problems before the Construction Industries, HMSO, London, UK.

European Commission (2006), ICT Uptake, Working Group 1, ICT Uptake Working Group draft Outline Report, October 2006, http://ec.europa.eu/enterprise/sectors/ict/files/wg1_report.pdf [Date accessed 11 September 2009]

Goulding J.S., Sexton, M.G., Zhang, X., Kagioglou, M., Aouad, G., and Barrett, P. (2007), “Technology Adoption: Breaking Down Barriers Using a Virtual Reality Design Support Tool for Hybrid Concrete", Journal of Construction Management and Economics, 25(12), 1239-1250.

Goulding J.S. and Alshawi, M. (2002), "Generic and Specific IT Training: A Process Protocol Model for Construction", Journal of Construction Management and Economics, 20(6), 493-505.

Grote, D. (2005), "Driving true development", Training, 42(7), 24-30.

Gyampho-Vidogah, R., Proverbs, D., Chen, D., Hold, G.D. and Moreton, R. (1999), "Cutting construction costs: EDMS as an administrative and communication tool", The International Journal of Construction Information Technology, Special Edition on Information Technology for Effective Construction Management, 7(2), 5972.

Gubrium, J.F, and Holstein, J.A. (2001), Handbook of Interview Research: Context and Method, Sage Publications, CA, USA.

Hammer, M. and Champy, J. (1993), Reengineering the Corporation: A Manifesto fort Business Revolution, Harper Business, New York, USA.

Hammer, M. and Stanton, S. (1995), The Re-engineering Revolution, Harper Collins, New York, USA.

Hanafizadeh, P., Hanafizadeh, M.R. and Khodabakhshi, M. (2009), "Taxonomy of e-readiness assessment measures", International Journal of Information Management, 29(3), 189-195.

Hartmann, T. and Fischer, M. (2009), "A process view on end-user resistance during construction IT implementations", ITcon, 14, Special Issue Next Generation Construction IT: Technology Foresight, Future Studies, Roadmapping, and Scenario Planning, 353-365.

Hjelt, M. and Björk, B.C. (2006), "Experiences of EDM usage in construction projects", Journal of Information Technology in Construction, 11, 113-25.

Hua, G.B., (2007), "Applying the strategic alignment model to business and ICT strategies of Singapore's small and medium-sized architecture, engineering and construction enterprises", Construction Management and Economics, 25(2), 157-169.

Huber, G.P. (1991), "Organizational Learning: The Contributing Processes and the Literatures", Journal of Organization Science, 2(1), 88-115.

Isikdag, U., Design patterns for BIM-based service-oriented architectures, Automation in Construction, Vol. 25, August 2012, pp. 59-71

Johnson, M. (2010) "Barriers to innovation adoption: a study of e-markets", Industrial Management \& Data Systems, 110(2), 157-174.

Jutla, D., Bodorik, P. and Dhaliwal, J., (2002), "Government support for the e-readiness of small and medium sized enterprises", Proceedings of the 35th Annual Hawaii International Conference on System Sciences, Hawaii, USA, DOI 10.1109/HICSS.2002.994081.

Kaplan, R.S. and Norton, D. P. (2004), "Measuring the Strategic Readiness of Intangible Assets", Harvard Business Review, February 2004, 52-63. 
Keillor, B.D. (2007), “Tools vs toys: does your technology work for you or play with you?”, Direct Marketing: An International Journal, 1(4), 211-217.

Kridan, A.B. and Goulding, J.S. (2006), "The Importance of Knowledge Management Implementation in the Banking Sector", VINE: The Journal of Information and Knowledge Management Systems, 36(2), 211-222.

Krigsman, M. (2010), “Understanding Marin County's \$30 million ERP failure”, ZDNet, http://www.zdnet.com/blog/projectfailures/understanding-marin-countys-30-million-erpfailure/10678?tag=nl.e539 [Date assessed 13 September 2010].

Kululanga, G.K, Price, A.D.F, and McCaffer, R. (1999), "Dynamics of Learning for Advancing Improvement in Organisations within Construction Industry", Proceedings of the CIB W55 \& W65 Joint Triennial Symposium, Cape Town, South Africa.

Kumaraswamy, M. (1997), "Improving Industry Performance Through Integrated Training Programs", Journal of Professional Issues in Engineering Education and Practice, 123(3), 93-97.

Latham, M. (1994) Constructing The Team, HMSO, London, UK.

Lee, A. and Sexton, M.G. (2007), "nD modelling: industry uptake considerations", Construction Innovation: Information, Process, Management, 7(3), 288-302.

Liebowitz, J. and Megbolugbe, I. (2003), "A set of frameworks to aid the project manager in conceptualizing and implementing knowledge management initiatives”, International Journal of Project Management, 21(3), 189-198.

Lientz, B. P. and Larssen, L. (2006), Risk Management for IT projects: how to deal with over 150 issues and risks, Elsevier, USA.

Lin, C., Pervan, G. and McDermid, D. (2007), "Issues and recommendations in evaluating and managing the benefits of public sector IS/IT outsourcing”, Information Technology and People, 20(2), 161-183.

Lou, E.C.W. and Alshawi, M. (2009), "Critical Success Factors for E-Tendering Implementation in Construction: People and Process Issues", ITcon, 14, 98-109.

Lou, E.C.W. and Goulding, J.S. (2010), "The pervasiveness of e-readiness in the global built environment arena", Journal of Systems and Information Technology, 12(3), 180 - 195

Loukis, E., Sapounas, I. and Aivalis, K. (2008), “The effect of generalized competition and strategy on the business value of information and communication technologies", Journal of Enterprise Information Management, 21(1), 24-38.

Love, P.E.D., Li, H., Irani, Z. and Holt, G. (2000), "Re-Thinking TQM: Toward a Framework for Facilitating Learning and Change in Construction Organizations", The TQM Magazine, 12(2) 107-116.

Love P.E.D., Irani, Z. and Edwards, D. J. (2005), "Researching the investment of information technology in construction: An examination of evaluation practices", Automation in Construction, 14(4), $20^{\text {th }}$ International Symposium on Automation and Robotics in Construction: The Future Site, 569-582.

Marsh, L. and Flanagan, R. (2000), "Measuring the costs and benefits of information technology in construction", Engineering, Construction and Architectural Management, 7(4), 423-435.

Mata, F.J., Fuerst, W.L. and Barney, J.B. (1995), "Information Technology and Sustained Competitive Advantage: A Resource-Based Analysis”, MIS Quarterly, 19(4), 487-505.

Michaelson, R. (2006), "Evaluating Failure: the case of UKeU", Proceedings of the 7th Annual Conference of the Higher Education Academy for Information and Computer Sciences, Trinity College, Dublin, Ireland.

Mulcahy, J.F. (1990) "Management of the Building Firm", Proceedings CIB 90, Joint Symposium on Building Economics and Construction Management, Sydney, Australia, 11-21.

Mutula, S.M, and van Brakel, P. (2006), An evaluation of e-readiness assessment tools with respect to information access: Towards an integrated information rich tool, International Journal of Information Management, 26(3), 212-223.

Nanoka, I. and Takeuchi, H. (1995), The Knowledge Creating Company-How Japanese Companies Create the Dynamics of Innovations, Oxford University Press, Oxford, UK.

Ngwenyama, O. K. and Lyytinen, K. J. (1997), "Groupware Environments as Action Constitutive Resources: A Social Action Framework for Analyzing Groupware Technologies", Computer Supported Cooperative Work: The Journal of Collaborative Computing, 6, 71-93.

Nitithamyong, P. and Skibniewski, M.J. (2004), "Web-based construction project management systems: how to make them successful?", Automation in Construction, 13(4), 491-506.

Noe, R. A. (2005), Employee training and development, $3^{\text {rd }}$ edition, McGraw Hill/lrwin, Boston, USA.

Nonaka, I. (1991), The Knowledge-creating Company, Harvard Business Review, November-December 1991.

Nonaka, I., and Takeuchi, H., (1995), The Knowledge Creating Company - How Japanese Companies Create the Dynamics of Innovation, Oxford University Press, Oxford, UK.

Offsey, S. (1997), “Knowledge Management: Linking People to Knowledge for Bottom Line Results”, Journal of Knowledge Management, 1(2), 113-122.

Partington, D. (2002) (Ed.), Essential Skills for Management Research, Sage Publications, London, UK

Peansupap, V. and Walker, D.H.T. (2004) "Strategic adoption of information and communication technology (ICT): case studies of construction contractors", in: Khosrowshahi, F (Ed.), $20^{\text {th }}$ Annual Association of Researchers in Construction Management (ARCOM) Conference, 1-3 September 2004, Heriot Watt University, 2, 1235-1245. 
Peansupap, V. and Walker, D.H.T. (2005), "Factors affecting ICT diffusion. A case study of three large Australian construction contractors", Engineering, Construction and Architectural Management, 12(1), 2137.

Peansupap, V. and Walker, D.H.T. (2006), "Information communication technology (ICT) implementation constraints: A construction industry perspective", Engineering, Construction and Architectural Management, 13(4), 364-379.

Potnis, D.D. (2010), "Measuring e-Governance as an innovation in the public sector", Government Information Quarterly, 27(1), 41-48.

Reddy, A.C. (1996), A Macro Perspective on Technology Transfer, Greenwood Publishing Group, CA, USA.

Robinson, H.S., Anumba, C.J., Carrillo, P.M. and Al-Ghassani, A.M. (2006), "STEPS: a knowledge management maturity roadmap for corporate sustainability", Business Process Management Journal, 12(6), 793-808

Rodríguez, I., and Meseguer, A., (2010), "Towards a dynamic model of e-commerce: environmental, technological and organisational drivers of B2C along time", Information Society, 26(3), 209-222.

Salah, Y. (2003), IS/IT Success and Evaluation: A General Practitioner Model, PhD Thesis, Research Institute for the Built Environment (BuHu), University of Salford, UK.

Sarabia, M. (2007), "Knowledge leadership cycles: an approach from Nonaka's viewpoint”, Journal of Knowledge Management, 11(3), 6-15.

Senaratne, A. and Sexton, M. (2008), "Managing construction project change: a knowledge management perspective", Construction Management and Economics, 26, 1303-1311.

Senge, P.M. (1990), "The Fifth Discipline: The Art and Practice of the Learning Organization”, Currency Doubleday, New York, USA.

Suermann, P. and Issa, R. (2009), "Evaluating industry perceptions of building information modelling (BIM) impact on construction", ITcon, 14, 574-594.

Soroor, J., Tarokh, M.J. and Keshtgary, M. (2009), "Preventing failure in IT-enabled systems for supply chain management", International Journal of Production Research, 47(23), 6543-6557.

Tse, R.Y.C. and Choy, L. (2005), "Is IT Training in Construction Industry Useful?", Journal of Construction Research, 6(1), 1-13.

Venegas, P. and Alarcón, L. (1997), "Selecting Long-Term Strategies for Construction Firms", Journal of Construction Engineering and Management, 123(4), 388-398.

Ward, J. and Daniel, E. (2005), Benefits Management: Delivering Value from IS \& IT Investments, John Wiley \& Sons, New York, USA.

Wiig, K. M. (1997), "Knowledge management: where did it come from and where will it go?", Journal of Expert Systems with Applications, 13(1), Special Issue on Knowledge Management, 1-14.

Zou, P.X.W. and Seo, Y. (2006) "Effective applications of e-commerce technologies in construction supply chain: current practice and future improvement", ITcon, 11, Special Issue e-Commerce in construction, 127147.

Zsidisin, G.A., Ellram, L.M., Carter, J.R. and Cavinato, J.L. (2004), “An analysis of supply risk assessment techniques", International Journal of Physical Distribution and Logistics Management, 34(5), 397-413. 
Figure 2. Scoping Study One: People Factor Enabler Rankings (score 1 ranks as most important, score 8 ranks as least important)

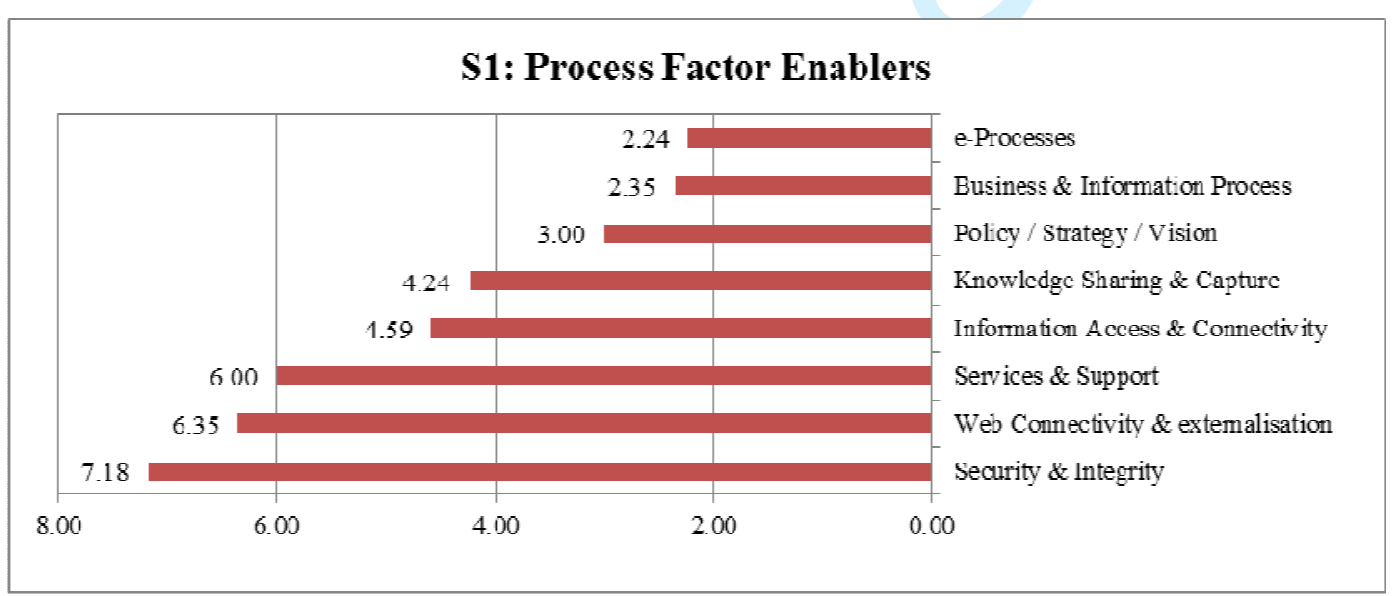

Figure 3. Scoping Study One: Process Factor Enabler Rankings (score 1 ranks as most important, score 8 ranks as least important) 


\section{S2 : Key E-Readiness Enablers for Construction}

Figure 4. Scoping Study One: People Factor Enabler Rankings (score 1 ranks as most important, score 8 ranks as least important)

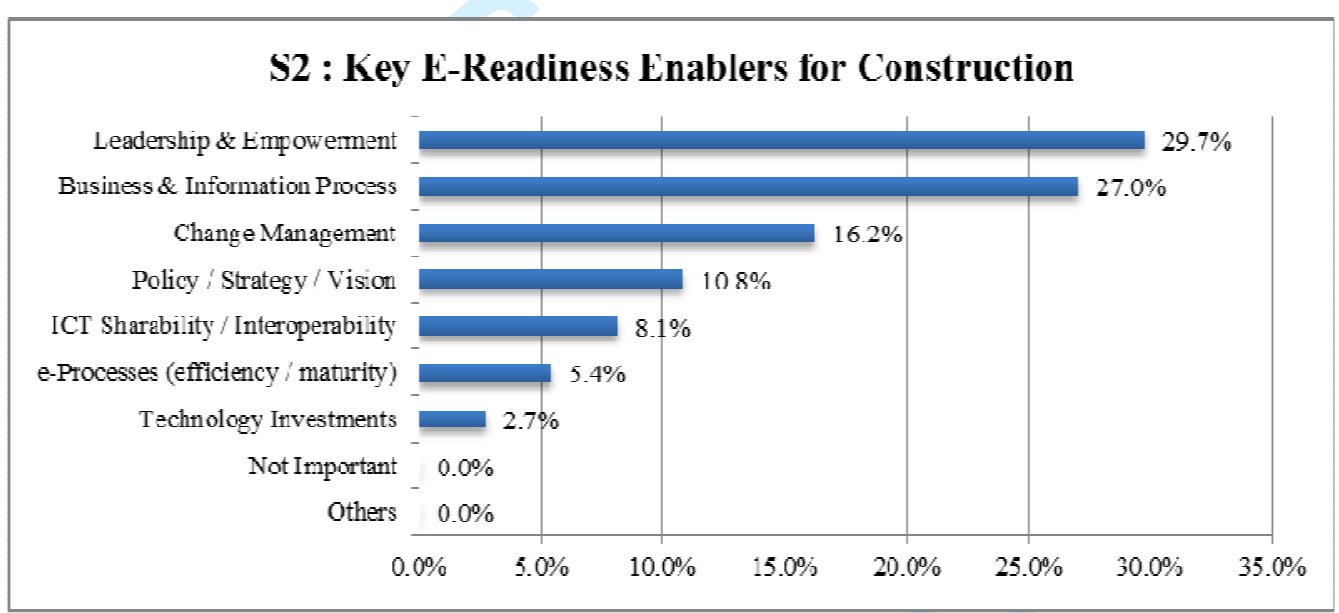

Figure 5. Scoping Study Two: Most Important E-Readiness Enablers for Construction

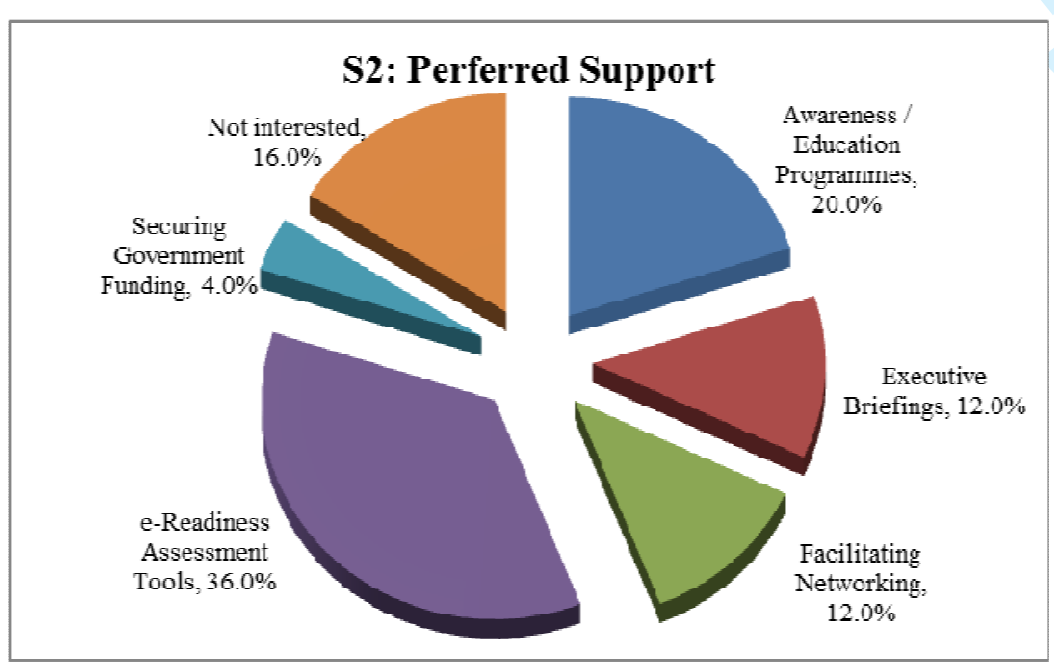

Figure 6: Scoping Study Two: Support Required to Achieve E-Readiness. 
Technology

Business \& Information Process Connectivity \& Security Information Access \& Connectivity ICT Infrastructure (hardware) Security \& Integrity Culture \& Society Information Access \& Connectivity

Human Capital \& Skills

$\begin{array}{ll}\text { Learning/Higher Education/Training } & \text { Policy / Strategy / Vision } \\ \text { Promotion \& Facilitation / Support } & \text { Knowledge Sharing \& Capture }\end{array}$ Change Management

Communication Services \& Support e-Processes (efficiency / maturity) ICT Reliability \& Support Use / Trial of New Technologies Technology Investments Management of Information Capacity Building
ICT Sharability / Interoperability Table 1: People, Process and Technology themes readiness enablers

\begin{tabular}{cll}
\hline Rank & \multicolumn{1}{c}{ Enabler } & \multicolumn{1}{c}{ Factor } \\
\hline 1 & Leadership \& Empowerment & People \\
2 & Change Management & People \\
3 & Business \& Information Process & Process \\
4 & Policy / Strategy / Vision & Process \\
5 & ICT Sharability / Interoperability & Technology \\
\hline Table 2: & Ranking of the Top Five E-Readiness Core Enablers
\end{tabular}

